\title{
Food Production Modelling Using Fixed Effect Panel Data for Nigeria and Other 14 West African Countries (1990- 2013)
}

\author{
Olatunji Taofik Arowolo ${ }^{1}$, Matthew Iwada Ekum ${ }^{2, *}$ \\ Department of Mathematics and Statistics, Lagos State Polytechnic, Ikorodu, Lagos, Nigeria
}

Email address:

saka_1972@yahoo.com (O. T. Arowolo),matekum@yahoo.com (M. I. Ekum)

${ }^{*}$ Corresponding author

\section{To cite this article:}

Olatunji Taofik Arowolo, Matthew Iwada Ekum. Food Production Modelling Using Fixed Effect Panel Data for Nigeria and Other 14 West African Countries (1990-2013). American Journal of Theoretical and Applied Statistics. Vol. 5, No. 4, 2016, pp. 208-218. doi: $10.11648 /$ j.ajtas.20160504.17

Received: May 22, 2016; Accepted: May 31, 2016; Published: July 8, 2016

\begin{abstract}
In this research, the fixed effect panel data predictive model was employed to formulate panel regression models of food production of 15 selected Economic Community of West African States (ECOWAS) using four (4) World Development Indicators (WDI) as explanatory variables. Data were collected from 1990 to 2013. The four WDI are Food imports (\% of merchandise imports), Agricultural land (\% of land area), Fertilizer consumption (kilograms per hectare of arable land) and Inflation (consumer prices annual \%). The fixed effect with cross-sectional seemingly unrelated regression (SUR) static panel data method was employed. The result of the analysis shows that agricultural land and fertilizer consumption have significant positive effect on the food production index of ECOWAS countries, while food imports and rate of inflation have significant negative effect on food production index of the ECOWAS countries. It is seen that $98.8 \%$ of the variation in food production among ECOWAS countries can be explained by the variations in food imports, agricultural land, fertilizer consumption and inflation. We therefore recommend that ECOWAS countries should increase agricultural land and fertilizer consumption and reduce food imports and rate of inflation in order to boost their food production level and have excess to export.
\end{abstract}

Keywords: Food Production Index, Cross Section, Time Series, Panel Data, Fixed Effect, World Development Indicators

\section{Introduction}

Modelling food production in this period of high cost of living in Nigeria and other West African country is sacrosanct. If only Nigeria and other West African countries can key into statistical modelling, maybe we would have moved pass the level we are now. The economy of Africa consists of the trade, industry, agriculture, and human resources. As of 2012, approximately 1.07 billion people were living in 54 different countries. Africa is a resource-rich continent but many African people are poor. Recent growth has been due to growth in sales in commodities, services, and manufacturing. Africa is the world's poorest inhabited continent, as measured by Gross Domestic Product (GDP) per capita. However, parts of the continent have made significant gains over the last few years. In recent years, African countries consist of the fastest growing economies in the world [1].

The United Nation Millennium Development Goals of reducing poverty by half, between 1990 and 2015, the proportion of people whose income is less than one dollar a day has energized the school of thought calling for Africa to redefine the importance of agricultural development. Wood (2002) argues that because it is land abundant, Africa will always have larger primary sector and smaller manufacturing sector than the land scarce regions of Asia and Europe [2].

West African countries (Benin, Burkina Faso, Cape Verde, Côte d'Ivoire, Gambia, Ghana, Guinea, Guinea Bissau, Liberia, Mali, Mauritania, Niger, Nigeria, St Helena, Senegal, Sierra Leone, and Togo) are experiencing rapid changes in the social and economic environment which are associated with changes in food consumption patterns. Specifically, increased food availability and diversity in urban areas affect the quality of diets and nutritional well- 
being. Changing consumption patterns often lead to new health conditions, which can be both positive and negative. While most countries in West Africa are still struggling to address problems of under-nutrition and micronutrient deficiencies, obesity and related chronic diseases have emerged as significant public health problems [3].

Agriculture and food production are important among ECOWAS countries, contributing larger percent to her GDP depending on the country. The importance of agriculture and food production in West Africa has not been stressed enough given that it is central to economic growth and most of the economic activities depend on it. Food production index (FPI) is used as a proxy to measure the food production wellbeing of a nation. The higher the FPI of a nation, the more improved the food production wellbeing of the nation.

\subsection{Significance of the Study}

Most West African countries do not rely on statistical or econometric models and this is why their economic growth is not sequential or do not have upward and consistent growth. Hence, most West African economies are non-model based. An econometric model specifies the statistical relationship that is believed to exist between the various economic variables pertaining to a particular economic phenomenon under study [4]. This research is therefore concerned in finding some relationships that exist among variables that can help to formulate predictive models that will be suitable for forecasting food production among West African countries. This model, if relied on would help to maintain steady growth in food production and food export among ECOWAS countries.

\subsection{Research Objectives}

This research is aimed at formulating panel fixed effect model for food production among selected West African countries. In order to achieve this aim, the following objectives must be achieved.

1. To study the behaviour of the Food Production Index (FPI) among selected West African countries using Time Plot.

2. To formulate a panel data fixed effect predictive model for the prediction and forecasting of food production among ECOWAS countries.

3. To identify the world development indicators, which have significant effect on nations' FPI.

4. To forecast FPI for Nigeria for year 2020.

\subsection{Scope and Limitations}

The scope of this research covers data from 1990 to 2013, spanning 24 years. The data include food production index (2004-2006 = 100), food imports (percentage of total merchandised imports of the country), agricultural land (percentage of total available land in the country), fertilizer consumption (kilograms per hectare of arable land) and inflation (consumer prices (annual \%)) of Nigeria and 14 other West African countries making a total of 15 West
African countries. In addition, data was collected on food exports (percentage of total merchandised exports of the country) for the linear model for the 15 countries.

The limitations of the research are:

The data used for this research is a secondary data, which has some limitations. We used secondary data because the nature of the data, which span over 24 years from 15 different West African countries, makes it impossible for an individual to collect primary data. The data is extracted from World Bank Databank and some other statistical materials from other statistical bodies, which may be subject to error since it is a secondary data. The topic under consideration is a panel data model with the following limitations, which includes problems in the design, data collection and data management of panel surveys. It is such that the nature of the data does not allow us to obtain primary data. Only some establishments like World Bank, the Central Bank of Countries, Statistical bodies like National Bureau of Statistics (NBS) have what it takes to obtain such data. It may not be completely free from error due to approximation.

\subsection{List of 15 Selected West African Countries Codes as Used by World Bank}

1) $\mathrm{BEN}=$ Republic of Benin

2) $\mathrm{BFA}=$ Burkina Faso

3) $\mathrm{GMB}=$ Republic of The Gambia

4) $\mathrm{GHA}=$ Republic of Ghana

5) $\mathrm{GNB}=$ Republic of Guinea-Bissau

6) GIN $=$ Republic of Guinea

7) $\mathrm{CIV}=$ Republic of Côte d'Ivoire

8) $\mathrm{LBR}=$ Republic of Liberia

9) MLI = Republic of Mali

10) $\mathrm{MRT}=$ Islamic Republic of Mauritania

11) NGA = Federal Republic of Nigeria

12) NER $=$ Republic of Niger

13) $\mathrm{SEN}=$ Republic of Senegal

14) $\mathrm{SLE}=$ Republic of Sierra Leone

15) $\mathrm{TGO}=$ Republic of Togo

\section{Theoretical Background}

The variables of interest in this research are food production index (FPI), which provides information on the level of growth in agriculture and balance of payment of the countries around the world including West African countries. Other variables that are of concern are the four world development indicators (WDI), which are food imports, agricultural land, fertilizer consumption and inflation rate. In this section, various literatures were reviewed.

West Africa has experienced very little progress in reducing food insecurity and child malnutrition in the past 20 years. Approximately, one third of children under five years of age are stunted, and 5-15 percent is wasted. Micronutrient deficiencies, particularly lack of vitamin A, iron and iodine, affect mainly women and children and contribute to some of the highest rates of child mortality in the world. Overweight and obesity are emerging problems in some urban 
populations with negative implications for chronic noncommunicable diseases. The causes of malnutrition and food insecurity are complex and include the agro-ecological, socio-economic and demographic characteristics of the subregion. Rising incomes, rapid population growth especially in urban areas, desertification, as well as HIV/AIDS affect the food system. Changes in diets and lifestyles especially in urban settings involve a shift from the consumption of traditional staples to imported cereals (wheat and rice). Although food availability has generally improved in the subregion, the dietary energy and protein supplies are still below requirements and unstable, especially in Sahel countries. The nutritional quality of local diets remains low for most people and access to adequate food is not always secure for the poor. Besides the need to diversify and increase food production and productivity, increased support is needed for appropriate food storage, processing, and preservation techniques at community and industrial level, and better distribution and marketing. Technologies, such as fortification and plant breeding, are increasingly relevant within a comprehensive food-based strategy. Nutrition education is a complementary activity for ensuring the effectiveness of food-based approaches. Based on a review of lessons learned from foodbased interventions implemented by FAO and other development partners, their paper addressed some of the major issues, challenges and opportunities involved in fulfilling the pledge of West African countries to meet the goal of reducing malnutrition by 50 percent in the nearest future [3].

Food insecurity is a major challenge for Niger and for many African countries. The purpose of their study is to investigate the factors influencing household food security in Niger, based on this, they collected data on 500 households, drought, high food prices, poverty, soil infertility, disease and insect attacks are reported by the respondents to be the main causes of food insecurity. Their empirical results from logistic regression revealed that the gender of the head of household, diseases and pests, labour supply, flooding, poverty, access to market, the distance away from the main road and food aid are significant factors influencing the odds ratio of a household having enough daily rations. Another important finding was that female-headed households are more vulnerable to food insecurity compared to male-headed households. Their findings provided evidence that food insecurity continues to affect the Nigerien population [5].

Relationship between policy, market access, country governance indicators and food production in 41 African countries based on a cross-country panel sample, a fixedrandom effect model was employed to test the hypothesis that beyond agricultural inputs and macroeconomic reforms other exogenous factors could foster food production. Their findings show that improving food-agricultural inputs enhance production, while conflicts, food aid and geographic location such as landlocked countries negatively affect food production. Exogenous factors influencing production response include rainfall, market access, and education. Both governance and education can indirectly improve food production by enhancing growth, through investment in infrastructures, and human capital [6].

The role of Nigerian agriculture in West African food security was studied and its implications on Nigeria's agricultural production, the potentials for Nigerian export of agricultural products to enhance regional food security, and the role that the Comprehensive Africa Agriculture Development Program (CAADP) could play in supporting agricultural research and development (R\&D) efforts in the region. The study was based on a critical review and analysis of secondary information on Nigerian agriculture in relation to cross-border trade and food security in the West Africa region. The data were obtained from the Central Bank of Nigeria $(\mathrm{CBN})$, the Food and Agricultural Organization statistical database (FAOSTAT), and databases of the Economic Community of West African States (ECOWAS) and the National Bureau of Statistics (NBS). The study showed that, on average, 17 percent of the 280 million people living in West Africa are still food insecure, while about 30 percent live below the poverty line. Thirty-three percent of children under five years of age are stunted, 28.3 percent are underweight, and 10 percent are wasted. Average dietary energy supply (DES), a measure of food security, ranges from $2,500 \mathrm{kcal}$ per capita per day in the coastal regions to 2,400 kcal per capita per day in the savannah regions. In terms of contribution to regional food security, however, Nigeria currently contributes only 51 percent of the total food supply in West Africa. Endowed with the largest agricultural potentials in the region, there are opportunities for Nigeria to contribute more to regional food security, when constraints such as low mechanization, inadequate access to improved inputs, poor markets, insufficient access to credit, policy inconsistency, and inadequate infrastructure are removed [7].

The factors that affect agricultural productivity in Imo State, Nigeria were identified. The method of proportionate random sampling technique was used in selecting a sample of 99 farmers who were interviewed using validated, structured questionnaire. Primary data collected were analyzed using frequencies, means, and the ordinary least squares multiple regression analysis technique. The results of the analysis show that the marginal value products estimated for farmland, planting materials, chemical fertilizer and labour are $0.0654,0.0615,0.0871$ and 0.0831 respectively. Yam/cassava/maize/vegetable/melon combination was identified as the main crop combination practiced by the farmers in the state. Analysis of resource use efficiency shows that the farmers are highly efficient in the use of planting materials but highly inefficient in the use of land and chemical fertilizer. The results of the multiple linear regression analysis on the determinants of agricultural productivity show that age, level of education, years of farming experience, farm size, extension contact, fertilizer use, planting materials and labour use are the main determinants of agricultural productivity in the state. It is recommended that extension agents should teach farmers to use the right quality and quantity of chemical fertilizers, and the use of high yielding planting materials to enhance 
farmers' productivity [8].

The role of agriculture transformation in the development process and as an engine to reduce poverty and improve general wellbeing through better access to nutrients in Africa was debated. To better inform the debate they reviewed food production, consumption and trade trends in a large sample of Sub-Saharan countries combining both macroeconomic and microeconomic evidence. They selected for the analysis nineteen countries for which household survey data was available, namely Benin, Burkina Faso, Burundi, Cameroon, Cote d'Ivoire, Ethiopia, Gambia, Ghana, Guinea Bissau, Kenya, Madagascar, Malawi, Mali, Nigeria, Rwanda, Senegal, South Africa, Tanzania and Uganda. The data shows that dietary energy has been increasing in Sub-Sahara Africa (SSA) but not steadily and not fast enough. The observed food production and consumption trends highlight the importance of pursuing a deep transformation of the agricultural sector in Sub Sahara Africa if incomes are to be risen and food security problems are to be mitigated [9].

Despite the critical importance of agriculture in SSA countries; there are constraints behind, between, and beyond the border that directly and indirectly affects agricultural export performance of these countries. His paper attempts to explain theoretically and assess empirically the demand and the supply side factors affecting agricultural export of SSA countries. Specifically, the study focuses on analyzing the relative importance of the two major factors in determining the countries agricultural export performance. Panel data set with fixed effects estimation technique is used to address the question. The data set covers $47 \mathrm{SSA}$ countries over the periods 2000-2008. The estimation result shows that on the supply side, factors such as real GDP, real GDP (lagged) of exporting country and lagged agricultural input use positively and significantly affects agricultural export of the SSA countries. The study also indicates that on the demand side the effect of per capita GDP of US, the major trading partner of SSA countries, is positive and significant. Moreover, the effect of US import tariff imposed on agricultural products from SSA countries is negative and significant. Therefore, the overall result reiterates that both supply side and demand side factors are equally important in determining agricultural export performance of SSA [10].

\section{Research Methodology}

Different types of data are generally available for empirical analysis, namely, time series, cross section, and panel. A data set containing observations on a single phenomenon observed over multiple time periods is called time series (e.g. FPI of a country for several years). In time series data, both the values and the ordering of the data points have meaning. In cross-section data, values of one or more variables are collected for several sample units, or entities, at the same point in time (e.g. FPI for 15 West African countries for a given year). Panel data sets refer to sets that consist of both time series and cross section data. This has the effect of expanding the number of observations available, for instance if we have 24 years of data across 15 countries, we have 360 observations. Although there would not be enough to estimate the model as a time series or a cross section, there would be enough to estimate it as a panel. However, in this research, the panel data model is preferred to time series and cross section model.

In a typical symbolic representation, time series variables are usually denoted by subscript $t$ while cross-sectional variables are denoted by subscript $i$. Since panel data have both time series and cross-sectional dimensions, their variables are represented by subscript it. Using the proposed model for this research, we can specify the following models in respect of this data set below:

$$
\begin{gathered}
y_{t}=\alpha+\sum_{w=1}^{k} \beta_{w} X_{w t}+e_{t}, t=1,2, \ldots, T \\
y_{i}=\alpha+\sum_{w=1}^{k} \beta_{w} X_{w i}+e_{i}, i=1,2, \ldots, n \\
y_{i t}=\alpha+\sum_{w=1}^{k} \beta_{w} X_{w i t}+e_{i t}, i=1,2, \ldots, n ; t=1,2, \ldots, T
\end{gathered}
$$

where $y$ denotes $F P I, X$ represents the explanatory variables $(F I, A L, F C$ and $I N F), t$ is time series dimension, $i$ is the cross-sectional dimension and $w$ is a counter for the explanatory variable while $k$ is the number of the explanatory variable used. Equation (1) above follows a time series framework, equation (2) follows a cross-sectional frame work while equation (3) follows a panel data framework [11].

\subsection{Panel Data Predictive Model (PDPM)}

Panel data models are broadly divided into two, namely Static Panel datamodels and Dynamic Panel Models. The most notable difference between the two models is the inclusion of the lagged dependent variable as a regressor in the latter. This exercise focuses on the static panel data models. A typical static panel data regression can be expressed as:

$$
y_{i t}=\alpha+\sum_{w=1}^{k} \beta_{w} X_{w i t}+e_{i t}
$$

In matrix form $y_{i t}=\alpha+X^{\prime}{ }_{i t} \beta+e_{i t}$, where

$w=1,2, \ldots, k$ (Regressors); $i=1,2, \ldots, n$ (Cross sectional units); $t=1,2, \ldots, T$ (Time periods),

where $Y$ is the dependent variable and $X_{w}$ are the explanatory variables. The subscripts ' $i$ ' and ' $t$ ' as earlier defined refer to cross-sectional dimension and time series dimension respectively, $e_{i t}$ is the composite error term which can be decomposed further into specific effects or individual observations (country effects as in the case of this research) and remainder disturbance term. There are two sets of specific effects namely the individual specific effects and time specific effects. If only one set of specific effects is included in the regression, such is referred to as one-way error components model. However, if both sets of specific effects are included, we refer to the model as two-way error components model. Equations (5), (6) and (7) show decomposition of $e_{i t}$ into one-way and two-way error components. 


$$
\begin{aligned}
e_{i t} & =\mu_{i}+v_{i t} \\
e_{i t} & =\lambda_{t}+v_{i t} \\
e_{i t} & =\mu_{i}+\lambda_{t}+v_{i t}
\end{aligned}
$$

where $\mu_{i}$ and $\lambda_{t}$ denote the unobserved individual and time specific effects respectively. We shall limit our empirical applications to the one-way error components.

\subsection{Static Panel Data Models (SPDM)}

The static panel data models can be estimated using:

1. Ordinary Least Squares (OLS)

2. Fixed Effects (FE)

3. Random Effects (RE)

4. Seemingly Unrelated Regression (SUR). (See [12]).

Each of these methods has its underlying assumptions which must necessary be satisfied to obtain unbiased and efficient estimates. We only considered the fixed effects model.

\subsection{Fixed Effects (FE)}

As earlier emphasized, one of the approaches used to capture specific effects in a panel data model is the fixed effects (FE) regression. Thus, equation (3) is modified using any of the error components equations (5), (6) or (7) depending on the specific effects being considered. The FE approach is based on the assumption that the effects are fixed parameters that can be estimated. Consequently, a number of econometric problems may be encountered:

i). the unobserved specific fixed effects may be correlated with the regressors employed;

ii). some of the regressors may be correlated with shocks (reminder disturbance term) that affect the dependent variable; and

iii). there is possibility of simultaneity biases resulting from the endogeneity of some regressors.

The FE approach can overcome these problems by using any of the three estimation methods namely: Within Group (WG) estimator; Least Squares Dummy Variable (LSDV) estimator and First Difference (FD) estimator. The WG estimator involves the deviation approach, which eliminates the unobserved effects. Similarly, the FD estimator involves taking the first difference of the modified panel data model to eliminate the unobserved effects. Thus, under the WG estimator and FD estimator, the model is transformed in such a way that the unobserved effect is eliminated. The LSDV estimator however involves the inclusion of dummy variables as regressors in the panel data model (equation 3 ) to capture the specific effects. In this case, either the intercept $\alpha$ or one of the dummy variables must be dropped to avoid perfect collinearity or dummy trap problem.

\subsection{Parameter Estimation}

From (4) in matrix form we have

$$
y=\alpha+X \beta+e,
$$

$$
y=\alpha J_{n T}+X \beta+Z_{\mu} \mu+v=Z \delta+Z_{\mu} \mu+v
$$

Where $Z$ is $n T \times(K+1)$ and $Z_{\mu}$, the matrix of country dummies is $n T \times n$. If $n$ is large, (8) will include too many dummies and the matrix to be inverted will be dimension $(n+K)$ ! Apart from the herculean task of having to invert such a large matrix, the matrix will also fall into dummy variable trap.

Rather than attempt OLS on (8), we can obtain Least Squares Dummy Variables (LSDV) Estimators of $\alpha$ and $\beta$ by pre multiplying (8) by $Q$ and performing OLS on the transformed model:

$$
Q y=Q \alpha J_{n T}+Q X \beta+Q Z_{\mu} \mu+Q v
$$

but $Q Z_{\mu}=Q \mathrm{~J}_{\mathrm{nT}}=0$ so that (9) becomes

$$
\begin{aligned}
& Q y=Q X \beta+Q v \\
& Q v=Q y-Q X \beta .
\end{aligned}
$$

Square $Q v$, differentiate the result and equate it to zero to minimize $Q v$

$$
\begin{gathered}
(Q v)^{\prime}(Q v)=(Q y-Q X \beta)^{\prime}(Q y-Q X \beta) \\
=y^{\prime} Q^{\prime} y-y^{\prime} Q^{\prime} X \beta-\beta^{\prime} X^{\prime} Q^{\prime} y+\beta^{\prime} X^{\prime} Q^{\prime} X \beta
\end{gathered}
$$

Let $S=(Q v)^{\prime}(Q v)$, so that we have

$$
\begin{gathered}
S=y^{\prime} Q y-2 \beta^{\prime} X^{\prime} Q y+\beta^{\prime} X^{\prime} Q X \beta \\
\frac{d S}{d \beta}=-2 X^{\prime} Q y+2 X^{\prime} Q X \beta \\
0=-2 X^{\prime} Q y+2 X^{\prime} Q X \hat{\beta}
\end{gathered}
$$

Therefore $\hat{\beta}=\left(X^{\prime} Q X\right)^{-1} X^{\prime} Q y$

Unbiasedness: $\hat{\beta}$ is an unbiased estimate of $\beta$

$$
\begin{gathered}
\hat{\beta}=\left(X^{\prime} Q X\right)^{-1} X^{\prime} Q y \\
E(\hat{\beta})=E[\beta]+\left(X^{\prime} Q X\right)^{-1} X^{\prime} Q E(v)
\end{gathered}
$$

Since $E(v)=0$, then $E(\hat{\beta})=\beta$.

Variance of $\beta$

$$
\begin{aligned}
& \hat{\beta}-\beta=\left(X^{\prime} Q X\right)^{-1} X^{\prime} Q v \\
& V(\hat{\beta})=E(\hat{\beta}-\beta)(\hat{\beta}-\beta)
\end{aligned}
$$

On substituting (10) into (11), we have

$$
V(\hat{\beta})=E\left[\left[\left(X^{\prime} Q X\right)^{-1} X^{\prime} Q v\right]\left[\left(X^{\prime} Q X\right)^{-1} X^{\prime} Q v\right]\right]
$$

Since $Q Q^{\prime}=Q$, we have

$$
V(\hat{\beta})=\left[\left(X^{\prime} Q X\right)^{-1} X^{\prime} Q\left[E\left(v v^{\prime}\right)\right] Q^{\prime} X\left(X^{\prime} Q X\right)^{-1}\right],
$$

but $E\left(v v^{\prime}\right)=\sigma_{v}^{2} I_{n T}$, so that

$$
\begin{gathered}
V(\hat{\beta})=\sigma_{v}^{2} I_{n T}\left[\left(X^{\prime} Q X\right)^{-1} X^{\prime} Q X\left(X^{\prime} Q X\right)^{-1}\right] \\
V(\hat{\beta})=\sigma_{v}^{2} I_{n T}\left(X^{\prime} Q X\right)^{-1}
\end{gathered}
$$

The OLS $\hat{\beta}=\beta+\left(X^{\prime} Q X\right)^{-1} X^{\prime} Q v$ is sometimes called 
the Least Squares Dummy Variable (LSDV).

\subsection{Fixed Effect Hypothesis Testing}

We may wish to hierarchically test the significance of the fixed effects model. We use the pooled regression model as the baseline for our comparison. We first test the group (country) effects. We can perform this significance test with an $\mathrm{F}$ test resembling the structure of the $\mathrm{F}$ test for $\mathrm{R}^{2}$ change between the fixed effects model and the pooled version.

$$
F_{\text {groupeffects }}=\frac{\left(R_{\text {fem }}^{2}-R_{\text {pooled }}^{2}\right) /(n-1)}{\left(1-R_{L S D V}^{2}\right) /(n T-n-k)}
$$

Here $T=$ total number of temporary observations, $n=$ the number of groups (countries) and $k=$ number of regressors in the model. If we find significant improvements in the $R^{2}$ then, we have statistically significant group effects.

The null and alternative hypotheses are given as follows:

$H_{0}: \mu_{1}=\mu_{2}=\ldots=\mu_{n}=0$ (Pooled) vs $H_{1}: \mu_{1} \neq \mu_{2} \neq \ldots \neq \mu_{n}=0$ (Fixed Effect).

\subsection{Model Specification}

In this research, a panel data predictive model (PDPM) is specified. A multiple linear regression model using food production index as the dependent variable and four world development indicators (food import, agricultural land, fertilizer consumption and inflation rate) as the predictor variables is specified as shown below; where

FPI $=$ Food Production Index

$\mathrm{FI}=$ Food Imports

$\mathrm{AL}=$ Agricultural land

$\mathrm{FC}=$ Fertilizer Consumption

INF $=$ Inflation Rate

$\beta_{i}=$ Unknown Parameters to be estimated

$\mu_{i}=$ Cross country fixed effect

$v_{i t}=$ Idiosyncratic error term

\section{Empirical Result}

The data collected from the World Bank data bank on FPI and four (4) other world development indicators (WDI) were used to formulate a panel data predictive model to forecast the FPI among selected ECOWAS, we regressed FPI on these four WDI using panel data predictive model. The four (4) world economic indicators are food imports, Agricultural land, fertilizer consumption and Inflation rate.

\subsection{Exploratory Data Analysis}

The panel data structure is of the form in Table 1. The first column of the table shows the country name, the second column shows the cross-section $i$, the third column shows the time $t$, the forth column shows the serial number of the dataset, the fifth column shows the years, the sixth to tenth columns shows the variables included in the model.

$F P I_{i t}=\beta_{0}+\beta_{1} F I_{i t}+\beta_{2} A L_{i t}+\beta_{3} F C_{i t}+\beta_{4} I N F_{i t}+\mu_{i}+v_{i t}$

Table 1. Panel Data Structure.

\begin{tabular}{|c|c|c|c|c|c|c|c|c|c|}
\hline Country & I & t & Sn & Year & FPI & FI & $\mathbf{A L}$ & FC & INF \\
\hline Benin & 1 & 1 & 1 & 1990 & 48.030 & 20.361 & 20.131 & 0.802 & 4.914 \\
\hline Benin & 1 & 2 & 2 & 1991 & 51.770 & 21.867 & 20.220 & 0.053 & 3.466 \\
\hline Benin & 1 & 3 & 3 & 1992 & 52.260 & 37.833 & 20.353 & 0.454 & 5.753 \\
\hline Burkina Faso & 2 & 1 & 25 & 1990 & 50.730 & 13.008 & 34.996 & 10.950 & -0.504 \\
\hline Burkina Faso & 2 & 2 & 26 & 1991 & 61.290 & 15.350 & 34.905 & 11.919 & 2.163 \\
\hline Togo & 15 & 22 & 358 & 2011 & 133.540 & 16.863 & 68.395 & 10.200 & 3.572 \\
\hline Togo & 15 & 23 & 359 & 2012 & 137.700 & 15.000 & 70.800 & 5.000 & 2.600 \\
\hline Togo & 15 & 24 & 360 & 2013 & 124.600 & 14.000 & 71.719 & 4.067 & 1.800 \\
\hline
\end{tabular}

Source: WorldBank database (2015a)

The exploratory data analysis using descriptive statistics showed the nature of the data collected and exposed some hidden features in the dataset. More importantly, we tested the assumptions of fixed effect model. The panel data model fitted by calculating parameters estimates and coefficient of determination $\left(R^{2}\right)$ and tested for the significance of the parameters is tested at $5 \%$ level of significance.

Republic of Benin

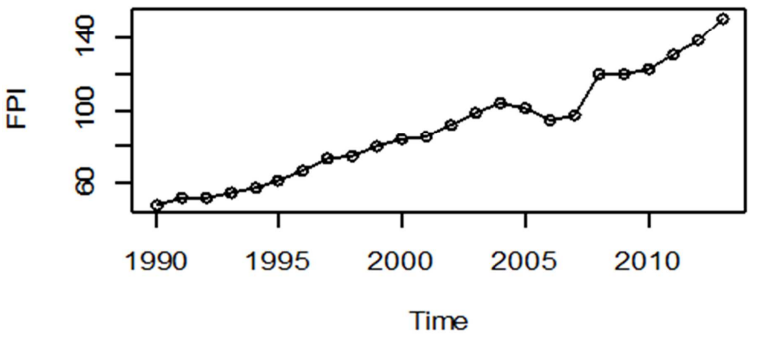

Burkina Faso

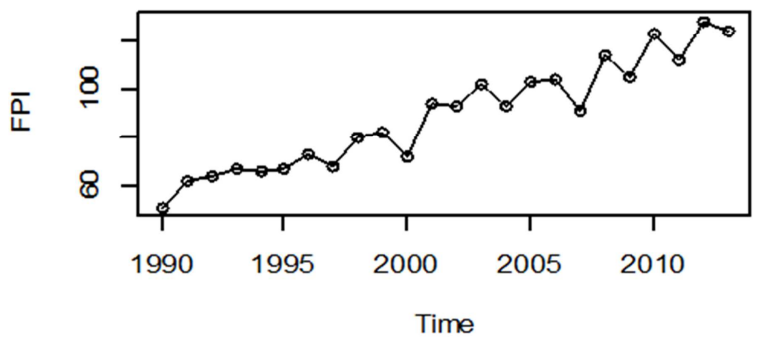


Republic of The Gambia

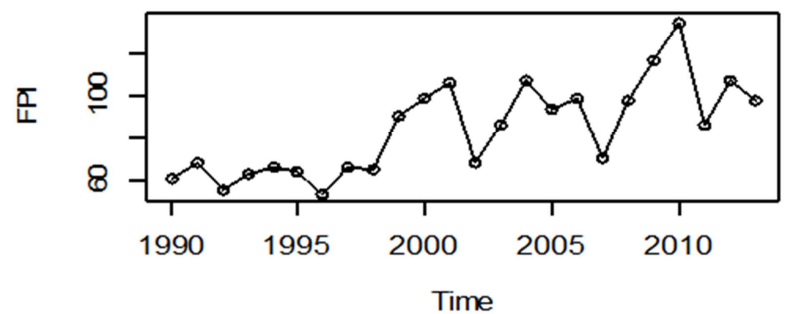

Republic of Guinea-Bissa u

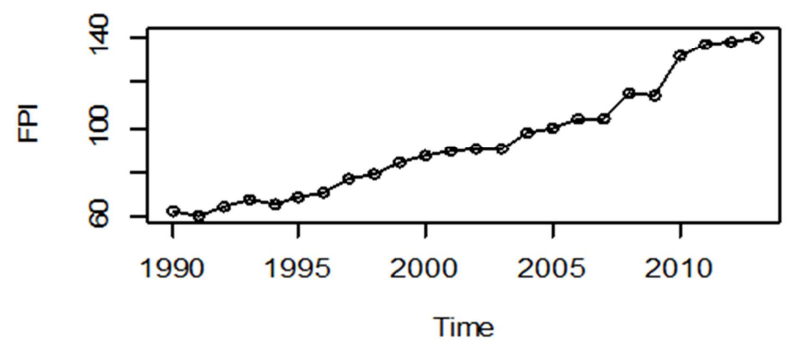

Republic of Côte d'Ivoire

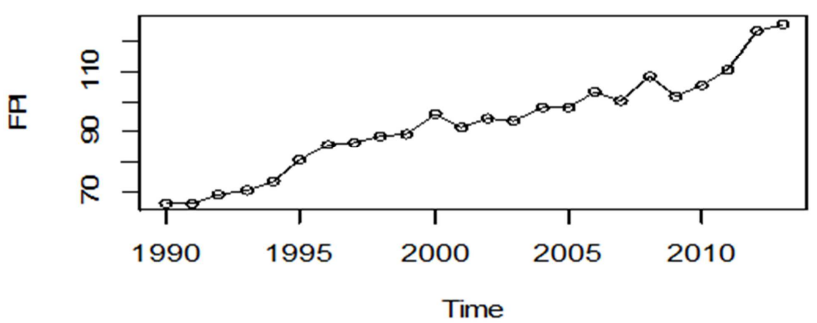

Republic of Mali

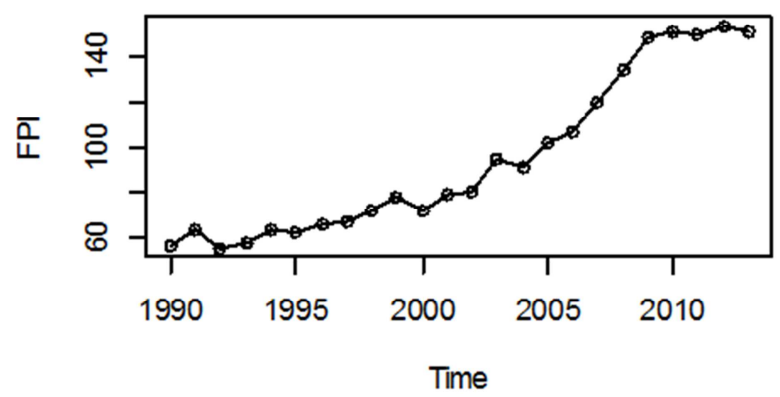

Republic of Niger

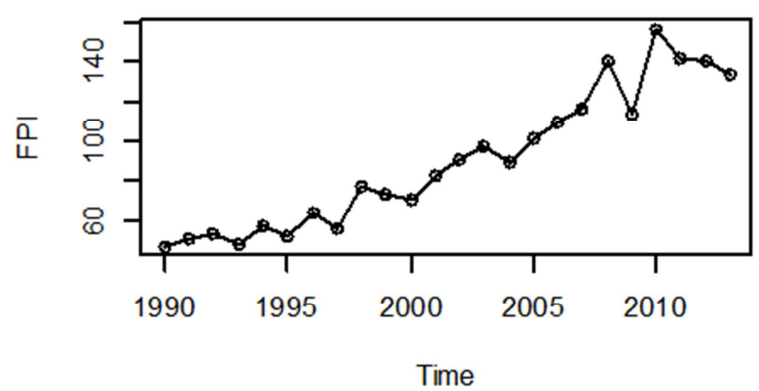

Republic of Ghana

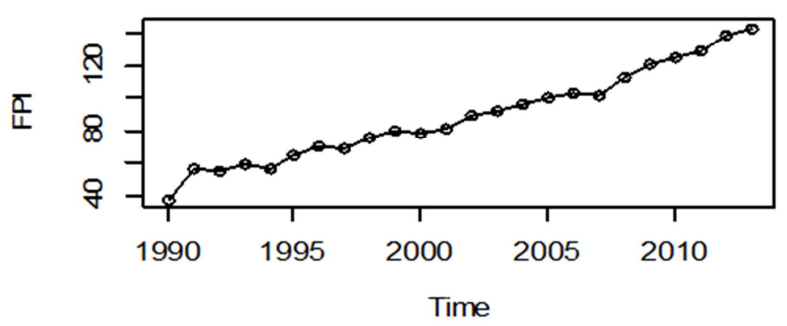

Republic of Guinea

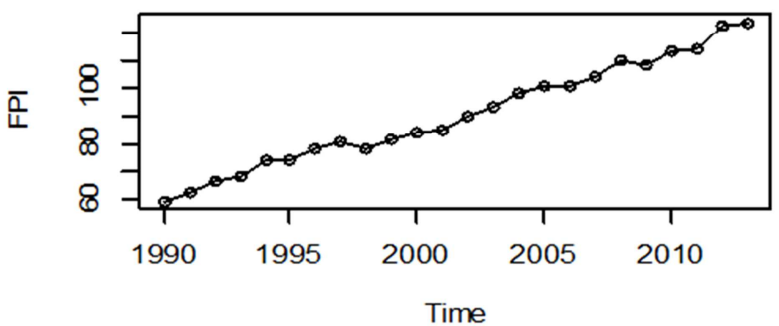

Republic of Liberia

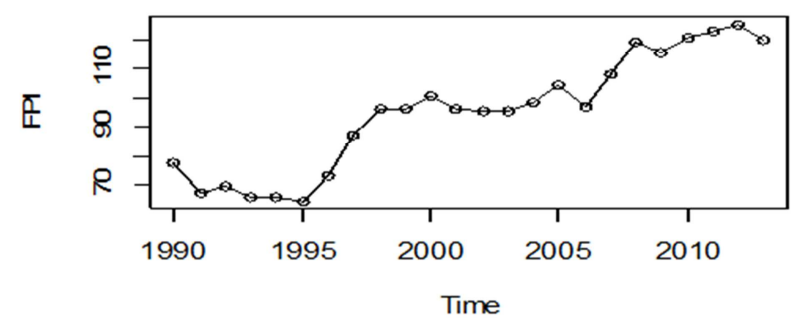

Islamic Republic of Mauritania

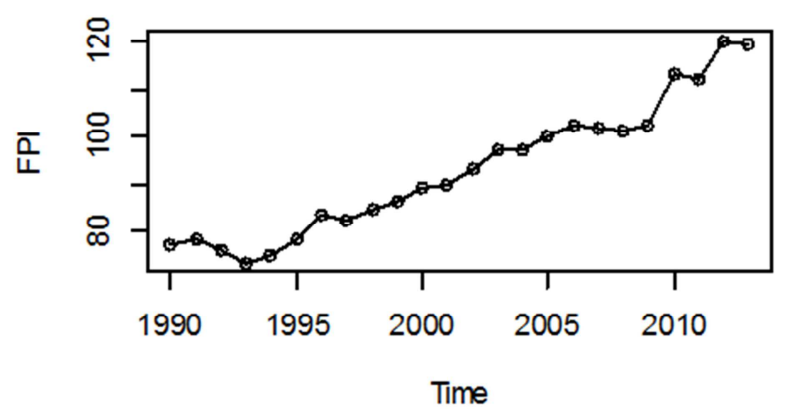

Federal Republic of Nigeria

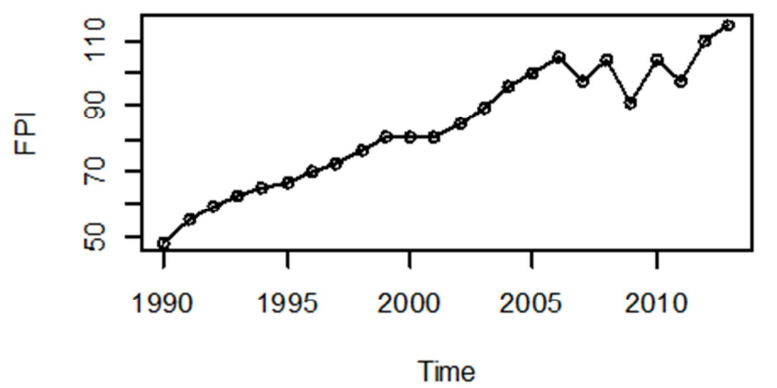


Republic of Senegal

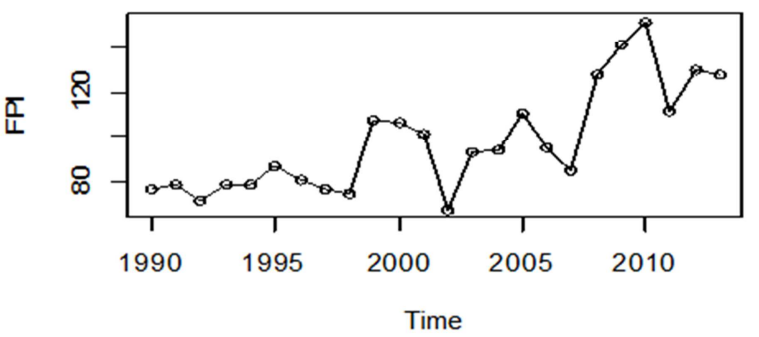

Republic of Togo

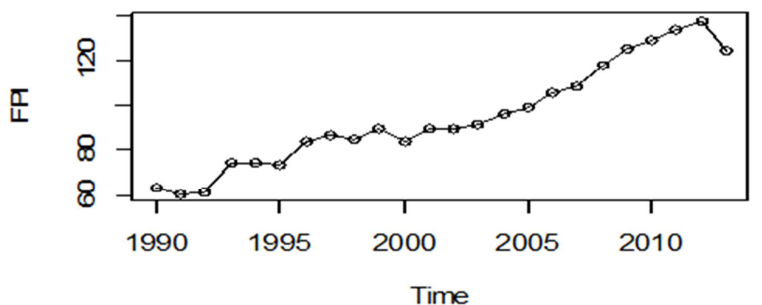

Republic of Sierra Leone

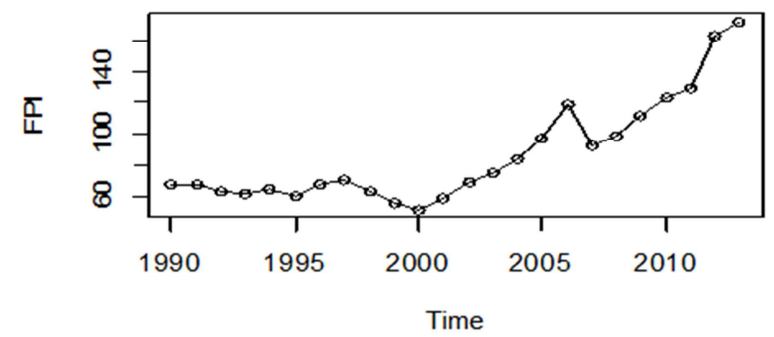

Figure 1. Time Plots Showing Food Production Index among Selected West African Countries 1990-2013 (24 Years).

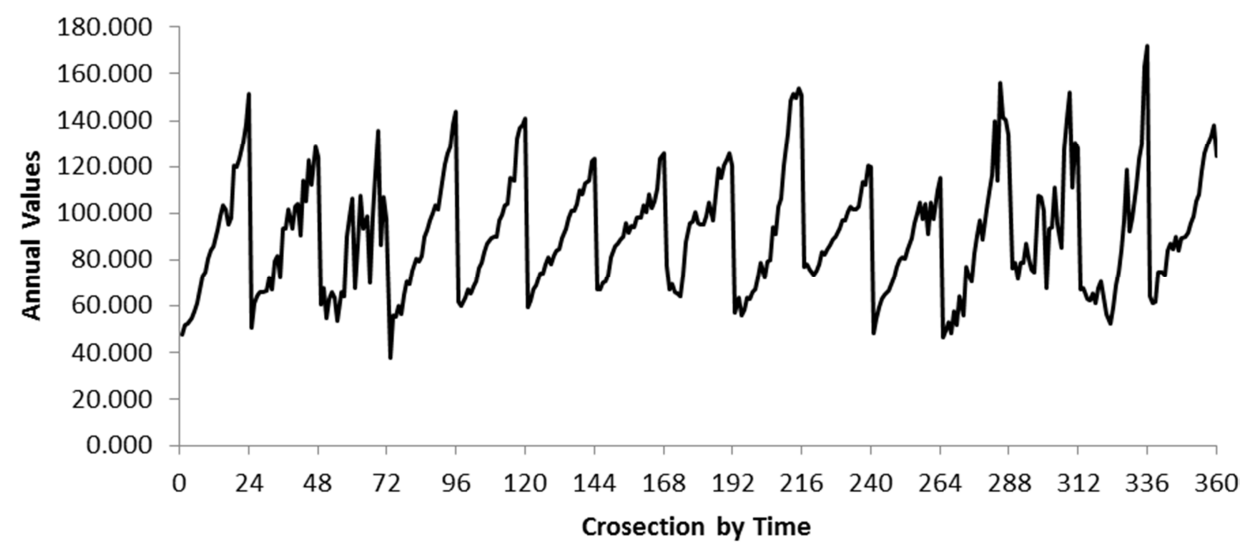

Figure 2. Panel Data Structure of Food Production Index (FPI).

Table 2. Descriptive Statistics of Variables Used.

\begin{tabular}{lllll}
\hline & FPI & FI & AL & FC \\
\hline Mean & 91.09900 & 24.06677 & 48.12391 & 9.324197 \\
Median & 89.81500 & 23.11250 & 47.78100 & 8.066500 \\
Maximum & 172.2000 & 62.41600 & 85.64200 & 52.04200 \\
Minimum & 37.57000 & 5.845000 & 20.13100 & -0.246000 \\
Std. Dev. & 25.10427 & 8.856276 & 15.75993 & 7.979338 \\
Skewness & 0.521380 & 0.594814 & 0.249958 & 1.645129 \\
Kurtosis & 2.817545 & 3.351377 & 2.175528 & -7.797000 \\
Observations & 360 & 360 & 360 & 7.596445 \\
\hline
\end{tabular}

\subsection{Data Analysis}

This section presents the empirical results of our model with the objective to assess the impact of some world development indicators (FI, AL, FC and INF) on variables on food production index for selected ECOWAS countries. Estimates are computed using the fixed effect static panel data model. The choice of this model is justified by the fact that the panel data pooled regression has not yielded robust estimators. Table 3 shows the results of the estimated fixed effect panel data model in one stage (one-way error) on 15 selected ECOWAS countries for the period 1990-2013.

In order to formulate a Panel data Fixed Effect Econometric Model, we used E-views 7, which made it convenient to use the Estimated Generalized Least Squares (EGLS) weight of cross-sectional seemingly unrelated regression (SUR).

Table 3 shows the model summary computed using the weighted fixed effects specifications. 
Table 3. Results of Food Production Index as Estimated with Fixed Effect Panel Model.

\begin{tabular}{|c|c|c|c|c|}
\hline \multicolumn{5}{|c|}{ Dependent Variable: FPI } \\
\hline \multicolumn{5}{|c|}{ Method: Panel EGLS (Cross-section SUR); Sample: 1990 - 2013} \\
\hline \multicolumn{5}{|c|}{ Periods included: 24; Cross-sections included: 15} \\
\hline \multicolumn{5}{|c|}{ Total panel (balanced) observations: 360} \\
\hline \multicolumn{5}{|c|}{ Linear estimation after one-step weighting matrix } \\
\hline Variable & Coefficient & Std. Error & t-Statistic & Prob. \\
\hline $\mathrm{C}$ & -180.1977 & 1.746516 & -103.1755 & 0.0000 \\
\hline FI & -0.139141 & 0.027038 & -5.146058 & 0.0000 \\
\hline $\mathrm{AL}$ & 5.695993 & 0.037666 & 151.2251 & 0.0000 \\
\hline $\mathrm{FC}$ & 0.231063 & 0.025271 & 9.143302 & 0.0000 \\
\hline INF & $\begin{array}{l}-0.169332 \\
\text { Effects Spe }\end{array}$ & 0.019618 & -8.631332 & 0.0000 \\
\hline \multicolumn{5}{|c|}{ Cross-section fixed (dummy variables) } \\
\hline & Weighted $\mathrm{S}$ & & & \\
\hline R-squared & 0.988333 & Mean dependent var & & 8.032567 \\
\hline Adjusted R-squared & 0.987717 & S. D. dependent var & & 36.54567 \\
\hline S. E. of regression & 1.007717 & Sum squared resid & & 346.2835 \\
\hline F-statistic & 1604.820 & Durbin-Watson stat & & 1.751443 \\
\hline Prob (F-statistic) & 0.000000 & & & \\
\hline
\end{tabular}

The panel regression model is thus fitted as:

$$
\widehat{F P} I_{i t}=-180.1977-0.139 F I_{i t}+5.696 A L_{i t}+0.231 F C_{i t}-0.169 I N F_{i t}+\mu_{i}
$$

where $\mu_{i}$ represents the countries fixed effects.

Each country fixed effect estimates, $\mu_{i}$ is given in Table 4. It shows the cross-section fixed effects one-way error component $\left(\mu_{i}\right)$ associated with each cross section.

Table 4. Cross Section Fixed Effects Estimates.

\begin{tabular}{lll}
\hline CROSSID & Countries & Effect \\
\hline 1 & Republic of Benin & 118.8704 \\
2 & Burkina Faso & 49.31115 \\
3 & Republic of The Gambia & -45.72961 \\
4 & Republic of Ghana & -89.57907 \\
5 & Republic of Guinea-Bissau & -38.62158 \\
6 & Republic of Guinea & -47.20690 \\
7 & Republic of Côte d'Ivoire & -84.54478 \\
8 & Republic of Liberia & 125.3412 \\
9 & Republic of Mali & 95.18978 \\
10 & Islamic Republic of Mauritania & 55.80914 \\
11 & Federal Republic of Nigeria & -188.4953 \\
12 & Republic of Niger & 99.83100 \\
13 & Republic of Senegal & 18.62981 \\
14 & Republic of Sierra Leone & 17.78524 \\
15 & Republic of Togo & -86.59042 \\
\hline
\end{tabular}

To forecast food production index for Nigeria in the year 2020, the model becomes

$$
\begin{aligned}
\widehat{F P} I_{11,2020}= & -180.2-0.14 F I_{11,2020}+5.7 A L_{11,2020} \\
& +0.23 F C_{11,2020}-0.17 I N F_{11,2020} \\
& -188.5
\end{aligned}
$$

$$
\begin{aligned}
\widehat{F P I} I_{11,2020}= & -180.2-0.14(5.845)+5.7(85.642) \\
& +0.23(52.042)-0.17(-7.797) \\
& -188.5
\end{aligned}
$$

$\widehat{F P} I_{11,2020}=130.372$

\subsection{Discussion}

The discussion is based on the empirical analysis result. The Time Series data for the 15 ECOWAS countries are presented in tabular form as shown in Table 1 and on time plots as shown in Figure 1. The time plots in Figure 1 depict that the general movement of the FPI shows an upward trend for the selected West African countries. However, there are some countries where there are up and down movements of the food production index as depicted on the time plot, but the general direction shows an upward trend. The most consistent countries are Ghana, Guinea and Guinea-Bissau, because their downward slide is minimal as compared to the other countries. Food production in Nigeria was consistent until 2007 when there was a downslide from 104.69 in 2006 to 97.46 in 2007 . These fluctuations continued until 2011, when it became stable and ever since be consistent and rose steadily from 97.8 in 2011 to 114.9 in 2013 and has continued to increase as depicted by the time plot of FPI of the Federal Republic of Nigeria.

The Time plot in Figure 2 shows the movements of food production index for the 15 selected countries over time (24 years) and it depicts a stationary process. Each country FPI depicts upward trend as shown by figure 2 for each 24 interval on the horizontal axis represents a country (crosssection).

It can be seen from Table 2 that the average food production index is 91.1 . It is also evident that the minimum food production index ever attained is 37.57 and the maximum ever attained is 172.2 .

The estimated values of the parameters (Constant, FI, AL, FC and INF) are $-180.1977,-0.139141,5.695993,0.231063$ and -0.169332 respectively, and all these estimated parameters are significant at $5 \%$ level. The value for the estimated coefficient of determination $\left(R^{2}\right)$ is 0.988 , meaning 
that $98.8 \%$ of the total variation in FPI could be explained by the variations in FI, AL, FC and INF, while just $1.2 \%$ could be explained by other variables not included in the model.

Based on the probability values of the estimates in the model, FI, AL, FC and INF are all significant. A unit increase in food import will lead to a significant reduction in FPI by $0.139 \%$ provided $\mathrm{AL}, \mathrm{FC}$ and INF are kept constant; if agricultural land increases by a unit then FPI will increase by $5.696 \%$ provided FI, FC and INF are kept constant; if fertilizer consumption increases by a unit then FPI will increase by $0.23 \%$ provided FI, AL and INF are kept constant, and if inflation rate increases by a unit then FPI will decrease by $0.169 \%$ provided FI, AL, and FC are kept constant.

In order to forecast the food production index of Nigeria for 2020, we assume some figures which are attainable. If by 2020, Nigeria should is able to reduce food import (\% of merchandise imports) from 18.0 of 2013 to 5.845, which was West Africa best produced by Ghana in 1987; and is able to increase Agricultural land (\% of land area) from 77.365 of 2013 to 85.642 , which was the region best produced by Nigeria in 2006; and is able to increase fertilizer consumption ( $\mathrm{kg}$ per hectare of arable land) from 3.767 of 2013 to 52.042 , which was the region best produced by Mali in 1991; and is also able to reduce inflation rate (consumer prices annual \%) from 8.5 of 2013 to -7.797 , which was the region best produced by Niger Republic in 1991, then the food production index of Nigeria in 2020 will be 130.372 as against 114.9 of 2013 .

\section{Conclusion}

The conclusions of this research are based on the discussion of the empirical result and the stated objectives.

The exploratory data analysis shows the behaviour of food production index among selected West African countries and it shows that there is upward trend in food production generally as was depicted by the time plot in figure 1 and figure 2. This supports the statement by Ekum et al, 2013 [1] that in recent years, African countries consist of the fastest growing economies in the world. Wood, 2002 [2] argues that because it is land abundant, Africa will always have larger primary sector and smaller manufacturing sector than the land scarce regions of Asia and Europe.

The expected panel data predictive model for the prediction and forecasting of food production among ECOWAS countries was formulated. The model shows that food import, agricultural land, fertilizer consumption and inflation rate have significant effects on ECOWAS nations' food production indices. The predictors included in ECOWAS countries' food production model signifies that $98.8 \%$ of the variation in food production could be explained by the variations in food imports, agricultural land, fertilizer consumption and rate of inflation. We conclude that Agricultural land and fertilizer consumption have positive effect on food production while foods imports and inflation rate have negative effect on food production.

\section{Recommendations}

Based on the conclusion drawn in the careful study of panel data predictive model of food production, the following recommendations are hereby made:

West African countries should take advantage of the vast arable land available and increase the percentage of such land for agricultural purposes because this will go a long way to improve food production among West African countries because agricultural land has significant positive effect on food production. Government and stakeholders should provide more fertilizers to farmers to encourage and improve fertilizer usage because fertilizer consumption also has a significant positive effect on food production.

On the other hand, food imports should be discouraged and inflation rate should be reduced because both food imports and inflation rate have negative effect on food production. This is supported by the fact that the region's share of global agricultural export has declined gradually. On the import side, the opposite pattern emerged as Sub-Saharan Africa is the only developing-country region that has seen its share of world agricultural imports increase rather than decrease [13, 14].

West African countries should increase food production and make it a priority over other aspect of the economy because if food production is in excess, there will be enough to export. The cause of poor export performance in agricultural sector, especially in food exports in West Africa has been attributed to poor domestic policies as well as restrictive policies by developed countries. Furthermore, the ability of the region to increase food exports is constrained by structural rigidities in food production capacity and food production is affected by anti-agricultural industrial policies $[15,16,17]$. Increasing food production will definitely increase food export and increase in food export will affect their balance of payment positively. This will go a long way helping the West African Sub-region to meet the United Nation Millennium Development Goals of reducing poverty.

\section{References}

[1] Ekum, M. I., Farinde, D. A. and Ayoola, F. J. (2013), "Panel Data: The Effects of Some World Development Indicator (WDI) on GDP Per Capita of Selected African Union (AU) Countries (1981-2011)", International Journal of Science and Technology (IJST Publications UK), vol. 2 No. 12, December, 2013. Pp 900-907.

[2] Wood, A. (2002), "Could Africa Be Like America?” A paper presented at the Annual Bank Conference on Development Economics, Washington, D. C. Available at: http://siteresources.worldbank.org/INTABCDEWASHINGTO N2002/Resources/Wood.pdf. Accessed on 25/05/2015.

[3] Lopriore, C. and Muehlhoff, E. (2010), "Food Security and Nutrition Trends in West Africa - Challenges and the Way Forward", Nutrition Programmes Service, Food and Agriculture Organization Rome, Italy.

[4] Samuelson, P. A., Koopmans, T. C. and Stone, J. R. N. (1954), "Report of the evaluative committee for Econometrica". Econometrica 22, 141-6. 
[5] Zakari, S., Ying, L. and Song, B. (2014), "Factors Influencing Household Food Security in West Africa: The Case of Southern Niger". Sustainability, 6, 1191-1202.

[6] Marcantonio, F. D, Opazo, C. M, Hurle J. B and Demeke, M (2014), "Determinants of Food Production in Sub Sahara Africa: The Impact of Policy, Market Access and Governance", Paper Presented at EAAE 2014 Congress (AgriFood and Rural Innovations for Healthier Societies), Ljubljana, Slovenia.

[7] Hedeh, L. (2013), "The role of Nigerian Agriculture in West African Food Security”, International Food Policy Research Institute (IFPRI). Jan 14, 2013. Available at http://nssp.ifpri.info/page/5/.Accessed on 25/05/2015.

[8] Obasi, P. C, Ukoha, H. A, Ukewuihe, I. S. and Mark, N. M. (2013). "Factors Affecting Agricultural Productivity among Arable Crop Farmers in Imo State, Nigeria", American Journal of Experimental Agriculture 3 (2): 443-454, 2013.

[9] Chauvin, N. D., Mulangu, F. and Porto, G. (2012), "Food Production and Consumption Trends in Sub-Saharan Africa: Prospects for the Transformation of the Agricultural Sector", African Center for Economic Transformation. Guido Porto, Universidad Nacional de La Plata, Working Paper, United Nations Development Programme, Regional Bureau for Africa, WP 2012-011: February 2012. Available at http://ideas.repec.org/p/rac/wpaper/2012-011.html (accessed March 10, 2015).
[10] Tesfaye, E. (2014), "Determinants of Agricultural Export in Sub-Saharan Africa: Evidence from Panel Study", American Journal of Trade and Policy, Vol. 1, No. 3, 2014 (Issue 3).

[11] Drukker, D. M. (2003), "Testing for serial correlation in linear panel-data models”. Stata Journal 3: Pp 168|177.

[12] Baltagi, B. H. (1980), "On seemingly unrelated regressions with error components", Econometrica 48, 1547-1551.

[13] Bacchetta, M. (2007), "Releasing Export Constraints: The Role of Governments", ERSD, WTO, available online at http://www.aercafrica.org/documents/export-supply-workingpaper/Bachetta 18DB37.pdf accessed on 15/03/,2015.

[14] World Bank (2007), "World Development Indicators", World Bank, Washington, D. C. Available at http://data.worldbank.org/indicator.Accessed on 25/05/2015.

[15] Biggs, T. (2007), "Assessing Export Supply Constraints: Methodology, Data, and Measurement", available online at http://www.aercafrica.org/documents/export_supply workingpapers/BiggsT- Assessing.pdf.Accessed on 15/03/2015.

[16] Kandiero, T. and Randa, J. (2004), "Agricultural Exports: Important Issues for Sub-Saharan Africa", African Development Review, Vol. 16, No. 1, Pp 1-35.

[17] Alemayehu, G. (1999), "Profile of Ethiopia's Export Performance", Proceedings of the Ethiopian Economic Association Annual Conference on the Ethiopian Economy, pp. 271-282. 